\title{
Efeitos do manejo do solo e da adubação orgânica no rendimento do algodoeiro ${ }^{1}$
}

\author{
Nilda B. de Lacerda ${ }^{2} \&$ José R. C. Silva²
}

\begin{abstract}
RESUMO
O presente trabalho teve como objetivo comparar a eficiência do plantio direto (PD), preparo convencional (PC) e os efeitos residuais de esterco bovino e de galinha na umidade do solo e no rendimento do algodão, em um Neossolo Flúvico. O experimento foi conduzido na Fazenda Experimental da UFC, em Pentecoste, CE. Os tratamentos testados, foram: algodão cultivado em sistema de plantio direto, utilizando-se 50 e $100 \mathrm{t} \mathrm{ha}^{-1}$ de esterco bovino (EBPD e 2EBPD) e $14,3 \mathrm{t}^{-1} \mathrm{de}^{-}$ esterco de galinha (EGPD); algodão cultivado em sistema convencional, com as mesmas doses de esterco bovino (EBPC e 2EBPC) e de esterco de galinha (EGPC) adotados no plantio direto. Avaliaram-se: altura de plantas, número de maçãs por planta, matéria seca da parte aérea, massa de capulho por planta, número de sementes por planta, massa de sementes e determinação da umidade do solo. O PD superou o PC no rendimento do algodão e melhorou a conservação da água e do solo e o seu uso pelas plantas. Em ambos os sistemas de manejo, o esterco de galinha foi o responsável pelos maiores aumentos, em todas as variáveis analisadas no algodão.
\end{abstract}

Palavras-chave: sistemas de manejo, esterco bovino, esterco de galinha

\section{Effect of soil management and the organic manure on cotton yield}

\begin{abstract}
The present work had as objective to compare the efficiency of no-tillage and conventional tillage as well as the residual effects of cattle and poultry manures used in these management systems with reference to soil moisture and cotton yield in a Fluvisol. The experiment was conducted at the UFC Experimental Farm in Pentecoste, in the State of Ceará, Brazil. The treatments tested were: cotton cultivated in no-tillage system using 50 and $100 \mathrm{t} \mathrm{ha}^{-1}$ of cattle manure (EBPD and 2EBPD) and $14.3 \mathrm{t} \mathrm{ha}^{-1}$ of poultry manure (EGPD); cotton cultivated in conventional system, with the same doses of cattle manure (EBPC and 2EBPC) and poultry manure (EGPC) adopted in the no-tillage. The height of plant, number of bolls per plant, dry matter of the aerial parts, weight of cotton per plant, number of seeds per plant, weight of seeds and content of soil water were evaluated. The no-tillage management system surpassed the conventional tillage in cotton yield and improved soil water conservation and its use by plants. In both management systems the poultry manure was responsible for the higher increases in all the analyzed cotton variables.
\end{abstract}

Key words: management systems, cattle manure, poultry manure 


\section{INTRODUÇÃO}

No Ceará, a situação da cultura do algodão se vem agravando nos últimos anos. O Estado plantou 1.039.740 ha de algodão na safra 1973/74, obtendo apenas $67.030 \mathrm{t}$ de pluma. A partir de então, a área cultivada vem sendo gradativamente reduzida, caindo para 755.530 ha na safra $84 / 85 ; 41.100$ ha na safra 1997/98; 29.400 ha na safra 2000/2001 e 16.487 ha na safra 2004 (Jornal da FIEC, 2002; IBGE, 2005). A disseminação maciça do bicudo (Anthonomus grandis) foi apontada como a causa principal do declínio (Barros et al., 1992), porém a erosão poderia ser uma razão muito mais significativa para o abandono dessa cultura, posto que a monocultura, uso de fogo ou pastejo dos restolhos, preparo convencional e ausência de conservação do solo e da água, são práticas generalizadas nas áreas algodoeiras.

Em função do manejo a que está submetido, o solo é passível tanto de degradação quanto de melhoramento em seu potencial produtivo, visto que este recurso natural está inserido em um ecossistema e, portanto, sujeito a variações dos demais componentes, tais como água, relevo, macro e microfauna e microflora, os quais podem ser afetados pelo homem. Um manejo inadequado do solo, ocasionando erosão acelerada, provoca perdas de produtividade (Silva et al., 1985; Dedecek, 1987; Tormena et al., 1998). É fundamental, portanto, que se apliquem sistemas de exploração agrícola visando não somente ao controle das perdas de terra e maior aproveitamento da água, mas, também, melhorar suas condições e propriedades físicas, facilitando o desenvolvimento e a nutrição das plantas. Para atender a esses objetivos o plantio direto, associado à adubação orgânica, apresenta-se como possível alternativa merecedora de estudos no Nordeste brasileiro.

Ante o exposto, o presente trabalho teve como objetivo comparar a eficiência do plantio direto e preparo convencional e os efeitos residuais de esterco bovino e de galinha na umidade do solo e no rendimento do algodão, em um Neossolo Flúvico.

\section{MATERIAL E MÉTODOS}

A pesquisa foi desenvolvida em solo classificado como Neossolo Flúvico (EMBRAPA, 1999), segundo a análise granulométrica, como do tipo franco, na Fazenda Experimental do Vale do Curu, administrada pelo Centro de Ciências Agrárias da UFC, localizada no município de Pentecoste, CE. A área do experimento se encontrava em sua terceira safra agrícola no período de maio a agosto de 1999, após o início da implantação, em março de 1997.

Antes da instalação do experimento (1997), foram coletadas amostras do solo proveniente dos $20 \mathrm{~cm}$ superficiais do perfil. Após a coleta, o solo foi encaminhado ao Laboratório do Departamento de Ciências do Solo/UFC; em seguida, submetido às análises físicas e químicas, segundo metodologia descrita no manual de métodos e análise de solo (EMBRAPA, 1997), cujos resultados se encontram na Tabela 1.

No primeiro ano (1997) a área foi cultivada com milho, no qual foi aplicado o esterco bovino e de galinha, no segundo
Tabela 1. Características físicas e químicas do solo (Neossolo Flúvico) da área experimental

\begin{tabular}{|c|c|}
\hline Características & Valor \\
\hline Areia $\left(\mathrm{g} \mathrm{kg}^{-1}\right)$ & 460 \\
\hline Silte $\left(\mathrm{g} \mathrm{kg}^{-1}\right)$ & 350 \\
\hline $\operatorname{Argila}\left(\mathrm{g} \mathrm{kg}^{-1}\right)$ & 190 \\
\hline Densidade global $\left(\mathrm{kg} \mathrm{dm}^{-3}\right)$ & 1,33 \\
\hline Densidade de partículas $\left(\mathrm{kg} \mathrm{dm}^{-3}\right)$ & 2,53 \\
\hline 0,033 MPa (\%) & 22,1 \\
\hline $1,5 \mathrm{MPa}(\%)$ & 14,2 \\
\hline pH em água & 7,3 \\
\hline Matéria orgânica $\left(\mathrm{g} \mathrm{kg}^{-1}\right)$ & 13,3 \\
\hline Fósforo disponível $\left(\mathrm{mg} \mathrm{kg}^{-1}\right)$ & 96 \\
\hline Potássio $\left(\mathrm{cmol}_{\mathrm{c}} \mathrm{kg}^{-1}\right)$ & 0,40 \\
\hline Cálcio $\left(\mathrm{cmol}_{\mathrm{c}} \mathrm{kg}^{-1}\right)$ & 7,60 \\
\hline Magnésio $\left(\mathrm{cmol}_{\mathrm{c}} \mathrm{kg}^{-1}\right)$ & 3,90 \\
\hline Sódio $\left(\mathrm{cmol}_{\mathrm{c}} \mathrm{kg}^{-1}\right)$ & 1,05 \\
\hline Soma de bases $\left(\mathrm{cmol}_{\mathrm{c}} \mathrm{kg}^{-1}\right)$ & 12,95 \\
\hline Hidrogênio + Alumínio $\left(\mathrm{cmol}_{\mathrm{c}} \mathrm{kg}^{-1}\right)$ & 0,17 \\
\hline Alumínio $\left(\mathrm{cmol}_{\mathrm{c}} \mathrm{kg}^{-1}\right)$ & 0,00 \\
\hline CTC $\left(\mathrm{cmol}_{\mathrm{c}} \mathrm{kg}^{-1}\right)$ & 13,12 \\
\hline Saturação de bases (\%) & 99 \\
\hline Nitrogênio total $\left(\mathrm{g} \mathrm{kg}^{-1}\right)$ & 0,6 \\
\hline Carbono $\left(\mathrm{g} \mathrm{kg}^{-1}\right)$ & 7,7 \\
\hline Relação C/N & 13 \\
\hline C.E. $\left(\mathrm{dS} \mathrm{m}^{-1}\right)$ & 2,64 \\
\hline
\end{tabular}

ano (1998) foi cultivada com algodão irrigado por gravidade (sulco) e no terceiro ano (1999) foi cultivado com algodão sem irrigação, vale ressaltar que o adubo orgânico só foi aplicado no primeiro ano, os cultivos subseqüentes foram avaliados em relação ao seu efeito residual.

Os tratamentos foram definidos como plantio direto (PD) e preparo convencional (PC). Para o ano agrícola aqui apresentado, utilizou-se a cultura do algodão herbáceo, cultivar CNPA-7H, sem irrigação, no espaçamento de $80 \times 25 \mathrm{~cm}$, e as unidades experimentais foram distribuídas de acordo com os seguintes tratamentos: EBPD: plantio direto em palha de cultivo anterior de algodão irrigado, plantado em sucessão ao milho adubado com $50 \mathrm{t} \mathrm{ha}^{-1}$ de esterco bovino; 2EBPD: igual a EBPD, substituindo-se a adubação por $100 \mathrm{t} \mathrm{ha}^{-1}$ de esterco bovino; EGPD: igual a EBPD, substituindo-se a adubação por 14,3 tha ${ }^{-1}$ de esterco de galinha; EBPC: plantio convencional, retirada a palha de cultivo anterior de algodão irrigado em sucessão ao milho adubado com $50 \mathrm{t} \mathrm{ha}^{-1}$ de esterco bovino; 2EBPC: igual ao EBPC, substituindo-se a adubação por $100 \mathrm{t} \mathrm{ha}^{-1}$ de esterco bovino; EGPC: igual ao EBPC, substituindo-se a adubação por $14,3 \mathrm{t} \mathrm{ha}^{-1}$ de esterco de galinha. O herbicida glifosato $\left(1,5 \mathrm{~L} \mathrm{ha}^{-1}\right)$ foi utilizado na dessecação e em dois cultivos químicos, enquanto no preparo convencional os cultivos foram realizados pelo método manual.

$\mathrm{O}$ delineamento experimental utilizado foi o inteiramente casualizado com três repetições; cada parcela apresentava 3 linhas de $4 \mathrm{~m}$ de comprimento, colhendo-se os dados da linha central em três plantas previamente sorteadas e marca- 
das aos 30 dias após emergência, as quais constituíram a unidade experimental.

No preparo do solo foram colocados $14,4 \mathrm{~kg}$ de restolho de algodão irrigado sobre a superfície do solo, correspondendo a $33 \%$ da cobertura nas parcelas do plantio direto. As parcelas de plantio convencional foram preparadas com o auxílio de enxada. Realizou-se a semeadura em 23/03/1999, por meio de covas distanciadas 25 e $80 \mathrm{~cm}$ entre linhas. Em cada cova foram colocadas 10 sementes e aos 15 dias após emergência das plântulas, realizou-se o desbaste, deixando-se apenas uma planta por cova.

Avaliaram-se as seguintes características: altura de plantas, número de maçãs por planta, matéria seca da parte aérea, massa de capulho por planta, número de sementes por planta, massa de sementes e determinação da umidade do solo, esta última realizada em cada parcela, com intervalo de 30 dias e amostragem com três repetições, com auxílio de trado, a uma profundidade de $25-30 \mathrm{~cm}$.

Os resultados das variáveis determinadas foram submetidos a análise de variância e o nível de significância foi ana- lisado através do teste "F" e as médias comparadas entre si pelo teste de Tukey, a 5\% de probabilidade. Utilizou-se o programa estatístico Minitab (Ryan et al., 1985).

\section{RESULTADOS E DISCUSSÃO}

Encontram-se, na Figura 1, os resultados referentes às características da cultura; observa-se, exceto para as variáveis altura de planta e matéria seca em EBPD, que ocorreu superioridade do plantio direto sobre o preparo convencional no rendimento do algodão, em todas as variáveis biométricas analisadas nos diferentes tipos e doses de adubo. $\mathrm{O}$ plantio direto proporcionou aumentos de 26, 50 e 30\% em massa de capulho por planta, nos tratamentos EBPD, EGPD e 2EBPD respectivamente, em relação ao preparo convencional em EBPC, EGPC e 2EBPC. Com relação ao número de sementes por planta nesta mesma seqüência de tratamento, os aumentos proporcionados pelo plantio direto em relação ao convencional foram de 21, 46 e 19\% e, na massa de sementes
A.

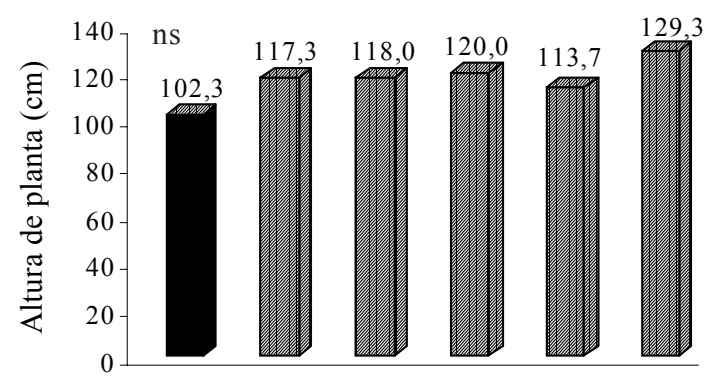

B.

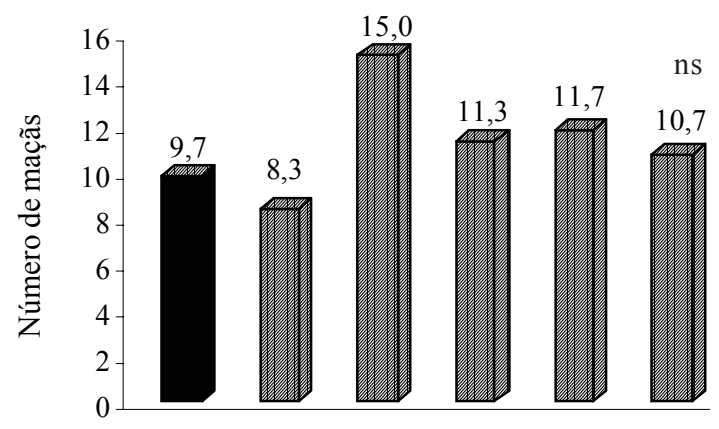

C.

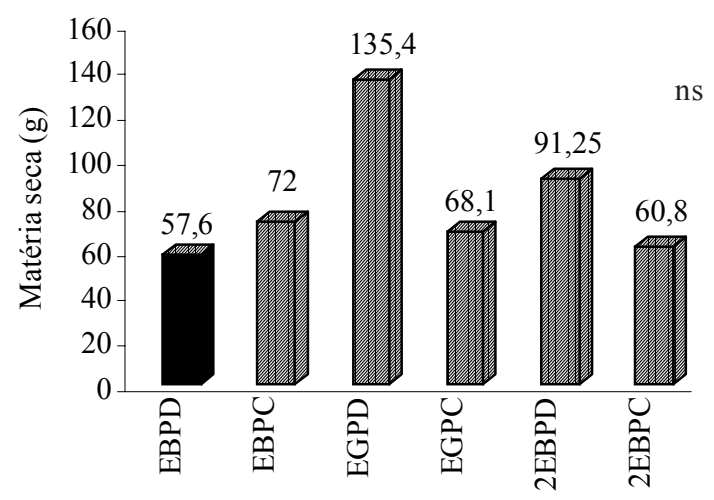

D.

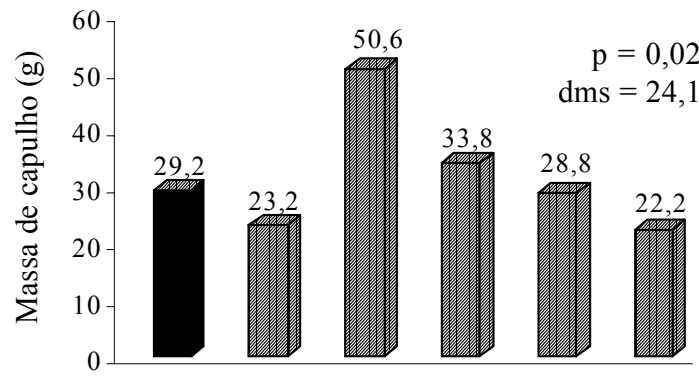

E.

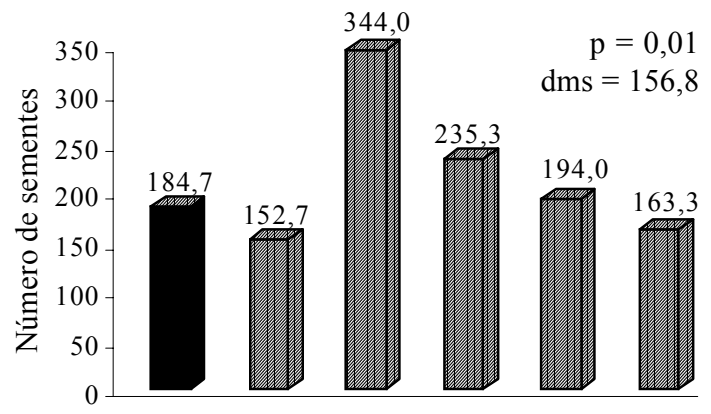

F.

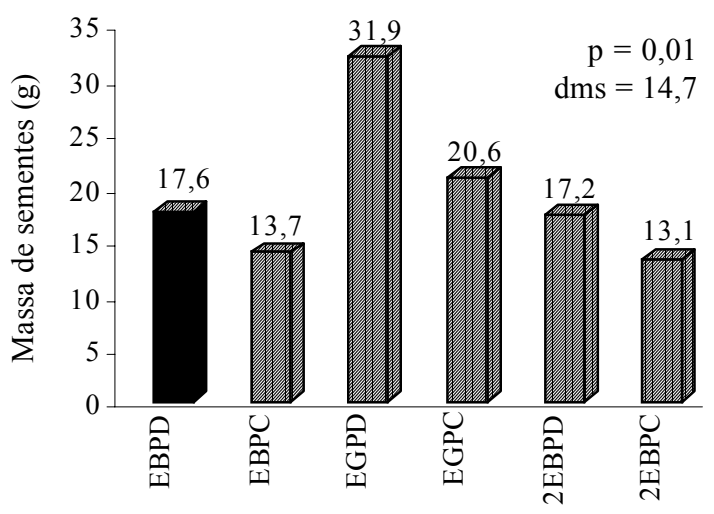

Tratamentos

Figura 1. Altura de planta (A), número de maçãs (B), matéria seca (C), massa de capulho (D), número de sementes (E) e massa de sementes (F), de algodão em sistema de manejo plantio direto adubado com 50 e $100 \mathrm{t} \mathrm{ha}^{-1}$ de esterco bovino (EBPD e 2EBPD) e 14,3 tha-1 de esterco de galinha (EGPD) e preparo convencional, adubado com 50 e 100 t ha $^{-1}$ de esterco bovino (EBPC e 2EBPC) e 14,3 tha ${ }^{-1}$ de esterco de galinha (EGPC) 
por planta, foram de 5,6, 5,7 e 11,3\%, respectivamente, sendo este aumento significativo apenas para o EGPD; para a variável número de maçãs, embora não tenha ocorrido diferença significativa, nota-se um aumento de 14, 25 e 9\% e na mesma seqüência dos tratamentos; para a matéria seca não se constatou diferença significativa entre os tratamentos, porém se observa aumento de 99 e 50\% nos tratamentos EGPD e 2EBPD respectivamente, em relação ao preparo convencional (EGPC e 2EBPC).

Os resultados estão de acordo com Melo Filho \& Silva (1993) e Possamai et al. (2001) que, trabalhando com comparação da produtividade do milho entre esses dois sistemas de preparo, observaram que o plantio direto foi superior ao preparo convencional; em contrapartida, Carvalho et al. (2004), trabalhando com adubação verde em sistema de manejo do solo na produtividade do algodoeiro, concluíram que o sistema de manejo do solo não interferiu na produtividade.

Considerando-se os efeitos residuais da aplicação dos adubos orgânicos e de suas diferentes doses, vê-se que, com exceção da variável altura de planta, o esterco de galinha foi o que proporcionou maiores aumentos de rendimento de todas as variáveis analisadas, tanto no plantio direto (EGPD) quanto no convencional (EGPC). No plantio direto, o tratamento EGPD aumentou a massa de capulhos por planta em $73 \%$ em relação aos tratamentos EBPD e $76 \%$ em relação a 2EBPD. Neste sistema conservacionista, o esterco de galinha também foi o que promoveu maior aumento em número de maçãs, matéria seca, número e massa de sementes por planta, superando o tratamento EBPD em 55, 135, 86 e $81 \%$ e o 2EBPD, em $28,48,77$ e $85 \%$ respectivamente; já no preparo convencional, os aumentos na massa de capulho por planta proporcionada pelo EGPC foram de 46 e 52\% em relação ao esterco bovino com $50 \mathrm{t} \mathrm{ha}^{-1}$ (EBPC) e $100 \mathrm{t} \mathrm{ha}^{-1}$ (2EBPC), respectivamente, para número de maçãs e número e massa de sementes por planta; nesta mesma seqüência se observa aumento de 36 e $6 \% ; 54$ e $44 \% ; 50$ e $57 \%$, respectivamente. A variável matéria seca apresentou, em EGPC, valores inferiores aos do EGPD.

Certamente os teores de N, P e K determinados, respectivamente, em valores 1,$4 ; 3,5$ e 2,2 vezes maiores no esterco de galinha em relação ao esterco bovino, foram responsáveis pela superioridade do primeiro. Por sua vez, a aplicação de dose dupla de esterco de bovinos praticamente não apresentou diferença de rendimento nos parâmetros biométricos do algodão; resultados semelhantes foram observados no cultivo anterior do milho, no mesmo solo em estudo (Silva \& Silva, 1998).

O plantio direto na palha, combinado com o esterco de galinha, apresentou produtividade equivalente a 2,6 $\mathrm{t} \mathrm{ha}^{-1} \mathrm{de}$ capulho em comparação com a obtida no preparo convencional $\left(1,1 \mathrm{t} \mathrm{ha}^{-1}\right)$. O rendimento no plantio direto superou as médias obtidas no Nordeste $\left(0,461 \mathrm{t} \mathrm{ha}^{-1}\right)$ e no Brasil $(1.314 \mathrm{t}$ $\mathrm{ha}^{-1}$ ) citados por Silva (2000); demonstrou-se, portanto, a clara superioridade do plantio direto, sugerindo-se evitar o preparo convencional, "antagônico à sustentabilidade" e que vem provocando elevadas perdas econômicas e agravando a erosão nos solos do Ceará. Os resultados encontrados no trabalho, comprovando a superioridade do plantio direto asso- ciado ao esterco de galinha sobre o preparo convencional, estão de conformidade com Carvalho et al. (1990); Carpenedo \& Mielniczuk (1990); Melo Filho \& Silva (1993); Santos et al. (1995); Pavan et al. (1996); Tormena et al. (1998); De Maria (1999) e Freitas (1999).

Verifica-se, na Figura 2, que o tratamento com esterco de galinha foi o responsável pelo maior rendimento do algodão, o solo sob plantio direto apresentou maior teor de água que o sob preparo convencional no início de crescimento do algodão; quando considerados apenas os meses de março e abril, já ocorreram 276,6 mm de chuvas. A partir de maio e até o final de agosto, com a redução das chuvas e gradativo crescimento do algodão até a maturação dos capulhos, o teor de água no solo foi menor sob plantio direto que sob preparo convencional. Ressalta-se que, embora os teores de umidade do solo nas datas amostradas se encontrem abaixo do ponto de murcha permanente (Tabela 1), as plantas apresentaram desenvolvimento normal com produtividade acima da média para o estado do Ceará.

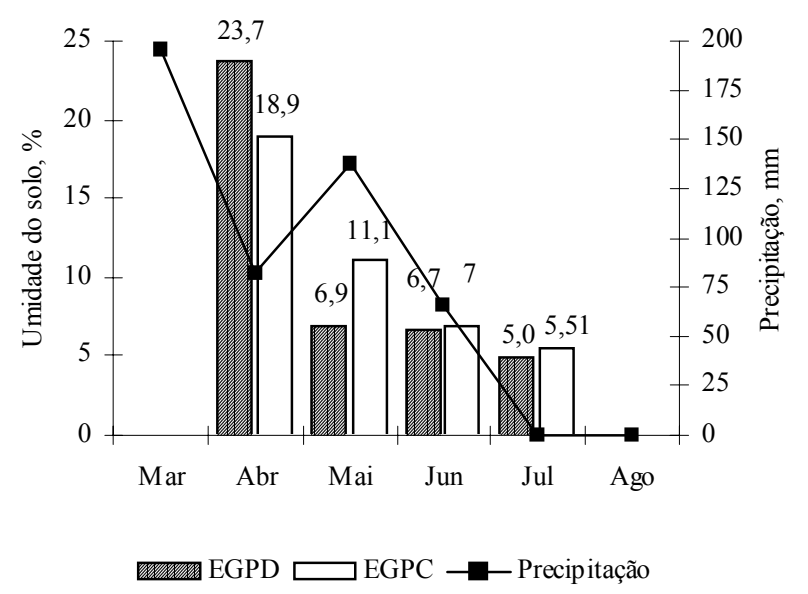

$\overline{\text { Figura 2. Precipitação e seqüência da umidade em EGPD e EGPC, no período de }}$ março a agosto de 1999

Tendência similar também foi constatada nos demais tratamentos, ou seja, o plantio direto superou o preparo convencional em conteúdo de umidade do solo, na fase inicial do ciclo da cultura, correspondente ao menor crescimento das plantas, porém na fase final de desenvolvimento das plantas, correspondente ao máximo de produção de biomassa, o teor de umidade do solo era maior no preparo convencional (Figura 3). Os dados aqui obtidos estão de acordo com os de Dantas (1995) que, trabalhando em um Podzólico Vermelho Amarelo, observou o mesmo comportamento.

Este aparente conflito pode ser explicado pelo aumento na produtividade do algodão nos tratamentos com plantio direto, significando que a água economizada pela cobertura da palha e conservada neste tratamento foi aproveitada para produzir plantas mais vigorosas e produtivas e, portanto, ao final do ciclo do algodão o teor de água no solo decresceu com relação ao do preparo convencional no qual se observou menor rendimento das plantas. Resultados semelhantes foram obtidos por Dantas (1995). 


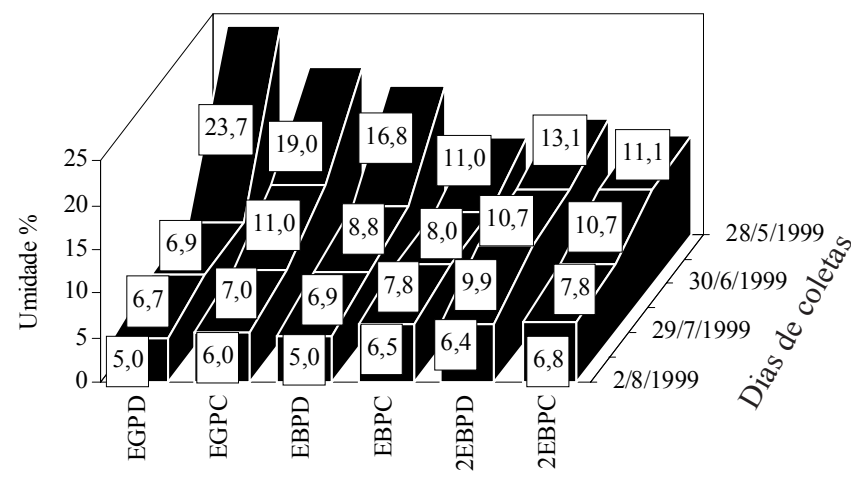

Tratamentos

Figura 3. Umidade do solo nos tratamentos plantio direto adubado com 50 e 100 t ha- ${ }^{-1}$ de esterco bovino (EBPD e 2EBPD) e $14,3 \mathrm{t} \mathrm{ha}^{-1}$ de esterco de galinha (EGPD) e preparo convencional, adubado com 50 e 100 t ha $^{-1}$ de esterco bovino (EBPC e 2EBPC) e 14,3 tha-1 de esterco de galinha (EGPC), no período de maio a agosto de 1999
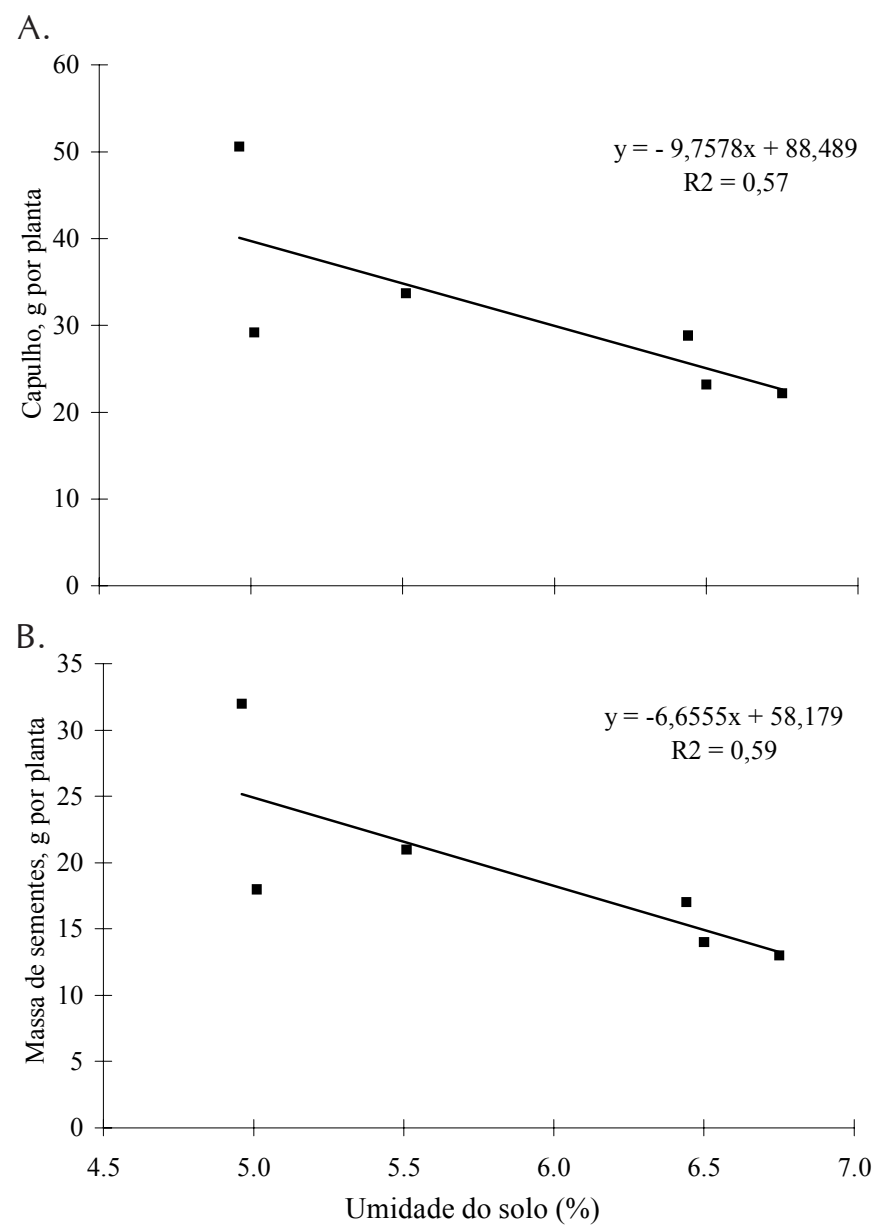

Figura 4. Relação entre a produção de capulho (A) e a massa de sementes (B), de algodão com teor de umidade do solo, ao final do experimento

No tratamento 2EBPD (Figura 3) constataram-se valores de umidade inferiores aos comparados com o EBPD; esses valores, porém, estão condizentes com o maior rendimento da cultura no primeiro, sugerindo-se que, como no plantio direto, a cultura utilizou a água armazenada para aumentar a produção.

A Figura 4 apresenta dados referentes a rendimento de capulhos e sementes de algodão; observa-se, em todos os tratamentos maior valor de produção correlacionado sempre por menor umidade do solo ao final do desenvolvimento da cultura, sugerindo maior potencialização no uso da água pelas plantas que apresentaram maior produtividade, confirmando resultados de Melo Filho \& Silva (1993) e Dantas (1995), que detectaram a eficiência da cobertura com palha no que se refere à transferência da água conservada para a formação de maior biomassa e produtividade das plantas. No final do ciclo da cultura constata-se umidade do solo abaixo do PMP, porém, deve-se ressaltar que esta não afetou o desenvolvimento e a produtividade da cultura. De acordo com a EMBRAPA (2005), as necessidades hídricas do algodoeiro variam com os estádios fenológicos, em função do desenvolvimento da sua fitomassa, apresentando um mínimo no estádio inicial, após a emergência, e um máximo, no estádio de floração. Embora o algodão exija os mais altos níveis de umidade no solo entre a floração e a formação das maçãs, e na frutificação, por etapas, é permitido que as plantas suportem um curto período de estresse, sem apresentar reduções consideráveis no rendimento.

\section{CONCLUSÕES}

1. O plantio direto superou o preparo convencional no rendimento do algodão em todas as variáveis analisadas, para todos os tratamentos, exceto na altura de planta e matéria seca, quando o esterco de bovinos foi utilizado na dose simples $\left(50 \mathrm{tha}^{-1}\right)$.

2. O efeito residual do esterco de galinha foi o que proporcionou maiores aumentos no rendimento, tanto em plantio direto quanto em plantio convencional.

3. O plantio direto foi mais eficiente que o preparo convencional na conservação da água e em sua utilização, proporcionando maior produção de biomassa e rendimento do algodão.

\section{LITERATURA CITADA}

Barros, M.A.L.; Santos, R.F. dos. Cavalcante, J.L. Efeito da expansão do bicudo no setor agrícola do Nordeste do Brasil. Relatório Técnico Anual, Campina Grande: EmbrapaCNPA, 1992, p84-87.

Carpenedo, V.; Mielniczuck, J. Estado de agregação e qualidade de agregados de Latossolo Roxo, submetido a diferentes sistemas de manejo. Revista Brasileira de Ciência do Solo, Campinas, v.14, n.1, p.99-105, 1990.

Carvalho, F.L.C.; Cogo, N.P.; Levien, R. Eficácia relativa de doses e formas de manejo do resíduo cultural de trigo na redução da erosão hídricas do solo. Revista Brasileira de Ciência do Solo, Campinas, v.14, n.2, p.227-234, 1990.

Carvalho, M.A.C. de; Athayde, M.L.F.; Soratto, R.P.; Alves, M.C.; Sá, M.E. de. Adubação verde e sistemas de manejo do solo na produtividade do algodoeiro. Pesquisa Agropecuária Brasileira. Brasília, v.39, n.12, p.1205-1211, 2004. 
Dantas, A.B. Controle da erosão, melhoramento das propriedades físicas e aumento da produtividade de Podzólico Vermelho Amarelo eutrófico pela cobertura morta com bagaço de cana-de-açúcar triturado. Fortaleza: UFC, 1995. 84p. Dissertação Mestrado

Dedecek, R.A. Efeitos das perdas e deposições de camadas de solo na produtividade de um Latossolo Vermelho-Escuro dos Cerrados. Revista Brasileira de Ciência do Solo, Campinas, v.13, n.2, p.323-328, 1987.

De Maria, I.C. Erosão e terraços em plantio direto. Sociedade Brasileira de Ciência do Solo. Boletim Informativo. Viçosa. v.3, n.24, p.17-21. 1999.

EMBRAPA - Empresa Brasileira de Pesquisa Agropecuária. Manual de métodos de análise de solo. 2.ed. Versão atualizada. Rio de Janeiro: CNPS, 1997. 212p.

EMBRAPA-Empresa Brasileira de Pesquisa Agropecuária. Centro Nacional de Pesquisa de Solos. Sistema brasileiro de classificação de solos. 1. ed. Brasília: Embrapa Produção de Informação. Rio de Janeiro: Embrapa Solos, 1999. 412p.

EMBRAPA - Empresa Brasileira de Pesquisa Agropecuária. Centro Nacional de Pesquisa de Algodão http:// sistemasdeproducao.cnptia.embrapa.br/FontesHTML /Algodao / AlgodaoIrrigado/index.htm. 21 Out.2005.

Freitas, P.L. Sistema de plantio direto e a sustentabilidade na agricultura. Sociedade Brasileira de Ciência do Solo. Boletim Informativo. Viçosa. v.3, n.24, p.25-28. 1999.

IBGE. Instituto Brasileiro de Geografia e Estatística http:// www.sidra.ibge.gov.br/bda/tabela/ listabl.asp?c $=1612 \& z=p \& o=18$. 15 Ago. 2005.

Jornal da FIEC. Parque Botânico: Preservação ambiental e ecocidadania. http://www.fiec.org.br/publicacoes/jornalfiec/edicoes/200502/default.asp. Abril/02 - ano XIII, n.168, 2002.

Melo Filho, J.F.; Silva, J.R.C. Erosão, teor de água no solo e produtividade do milho em plantio direto e preparo convencional de um Podzólico Vermelho-Amarelo no Ceará. Revista Brasileira de Ciência do Solo, Campinas, v.17, n.2, p.2912971, 1993.
Pavan, M.A.; Caramori, P.H.; Androcioli Filho, A.; Schollz, M.F. Manejo da cobertura do solo para formação e produção de uma lavoura cafeeira. Pesquisa Agropecuária. Brasileira, Brasília, v.21, n.2, p.187-192, 1996.

Possamai, J.M.; Souza, C.M. de; Galvão, J.C.C. Sistema de preparo do solo para o cultivo do milho safrinha. Bragantia, Campinas, v.60, n.2, p.79-82, 2001.

Ryan, B.F.; Joiner, B.L.; Ryan Jr., T.A. Minitab Handbook. 2.ed. Boston: PWS-KENT Publishing Company. 1985. 376p.

Santos, H.P dos.; Tom, G.O.; Lhamby, J.C.B. Plantio direto versus convencional: Efeito na fertilidade do solo e no rendimento de grãos de culturas em rotação com cevada. Revista Brasileira de Ciência do Solo, Campinas, v.19, n.2, p.449-454, 1995.

Silva, J.R.C. Erosão e produtividade nos solos do semi-árido. In: Oliveira, T.S.de; Assis Jr., R.N.; Romero, R.E. Agricultura, sustentabilidade e o semi-árido. Fortaleza: UFC/SBCS, 2000. cap.10, p.169-213.

Silva, J.R.C.; Coelho, M.A.; Moreira, E.G.S.; Oliveira Neto, P.R. Efeitos da erosão na produtividade de dois solos da classe Latossolo Vermelho-Amarelo. Ciências Agronômicas, Fortaleza, v.16, n.1, p.55-63,1985.

Silva, J.R.C.; Silva, F.J. de. Eficiência de dois níveis de adubação orgânica com esterco de galinha e bovino no rendimento de milho irrigado em solo Neossolos Flúvicos. Reunião Brasileira de Manejo e Conservação do Solo e da Água, 12, 1998, Fortaleza. Resumos...Fortaleza: SBCS/UFC/DCS, 1998. p.114-115.

Tormena, C.A.; Roloff, G.; Sá, J.C.M. Propriedades físicas do solo sob plantio direto influenciadas por calagem, preparo inicial e tráfego. Revista Brasileira de Ciência do Solo, Campinas, v.22, n.2, p.301-309, 1998. 